\title{
APPLICATION OF ECOLOGICAL MODELS FOR ASSESSMENT OF SUSTAINABILITY
}

\author{
S.E. JØRGENSEN \\ Copenhagen University, Denmark.
}

\begin{abstract}
There has lately been an increased interest in sustainability assessment, and models have been developed to assess the sustainability of a well-defined area, for instance, a landscape, a region, or an island. The model includes not only ecological processes but also socio-economic activities. Our experiences with sustainability assessment projects are still very limited, but from many sides it has been proposed which key variables to include in such an analysis. The use of work energy as a sustainability indicator that includes expressions of natural and socio-economic activities has been proposed and also tested with reasonable success. The efficiency of the use of work energy in general and the amount of work energy needed to maintain the various subsystem and their capacity of work energy were included in this analysis. It is, however, clear that one indicator is insufficient to assess the sustainability of a very complex system. It has, therefore, been proposed to supplement the use of work energy as an indicator with the development of models of the most important element cycles for natural and socio-economic systems, namely the cycles of carbon, nitrogen, and water. Two ecological factors are in focus when it is discussed what is important to include in a sustainability analysis, namely the services offered by the ecosystems and the biodiversity, which is important for the spectrum of resistances to possible impacts on the systems. It is important to include these two ecological factors as direct indicators in the sustainability analysis, although they both to a certain extent are covered by the work energy analysis. Socio-economic indicators are, of course, also needed but it is beyond the scope of this article.

The result of use of models for the assessment of the global sustainability by the use of a 'limits to growth' like model is presented. The model has been used to assess the global development in the case of: (1) more support to the developing countries by the industrialized countries, (2) more green tax, (3) more investment in pollution control, and (4) more investment in education and research. It can be shown that these investments lead to a win-win situation.

Keywords: biodiversity, ecosystem services, element cycling, exergy, sustainability, work energy.
\end{abstract}

\section{INTRODUCTION: THE CONCEPT OF SUSTAINABILITY}

To understand the concept of sustainability, it is necessary to turn around the various definitions [1], although they all are consistent with the general concept that we are obliged to give to our children the same freedom of possibilities as we have inherited from our parents [2]. This requires maintaining the Earth's capacity to provide services, but we will also apply the definition as used by Neumayer [3]. He uses the following summarizing, short, and clear definition for a sustainable development: one that maintains the capacity to provide non-declining per capita utility for 'infinity'.

Sustainable development is strongly dependent on the available resources. For instance, without the relatively cheap sources of fossil fuel energy that humanity has exploited in the last more than hundred years, the fast increase in the GNP per capita and the available technology that has characterized many countries, particularly the industrialized countries, would not have been possible. Resources have been utilized at an increasing rate in the last one hundred years, and continued resource depletion at the same accelerating rate would hinder future generations to have the same standard of living as we have enjoyed. Using the sustainability concept in environmental management is based upon the idea that we ought to maintain nature's diversity, functionality, and services capacity as well as its beauty [4].

We distinguish between weak and strong sustainability. Weak sustainability requires the sum of all forms of capital (natural capital and man-made capital) to be maintained at the same level. 
According to this definition, human-made capital can replace natural capital as long as the total sum is constant. The proponents of weak sustainability hold [3]) as follows:

1. Most natural resources are superabundant.

2. The elasticity for substituting human-made capital for resources in the production function is equal to or greater than unity, even in the limit of extremely high output resource ratios.

3. Technical progress can overcome any resource constraint.

Strong sustainability is defined according to [3] as follows:

1. Renewable resources are not used at a higher rate than the rate of renewal.

2. Non-renewable resources should not be used at a higher rate than alternatives could be developed in due time before the resources are exhausted.

3. The rates of pollution emissions should be adjusted to the rate at which ecosystems can decompose and adsorb the discharged pollutants.

The real issue is, therefore, to sustain natural capital and not to accept its unlimited substitutability, which is one of the main assumptions of weak sustainability. Weak sustainability is a move in the right direction; but it is insufficient. It is, of course, better to compensate a loss of natural capital with human-made capital; but, as we are strongly dependent on nature, it is necessary to maintain the natural capital, independent of augmentations in the human-made capital.

\section{WORK ENERGY}

A very general and holistic sustainability analysis uses the concept work energy as the basis for assessment. It is important to distinguish between energy that can and cannot do work. Energy is conserved in accordance with First Law of Thermodynamics, i.e. the amount remains constant, but according to the second law, all activities reduce the useful energy that can do work.

One of the messages of this article is that natural systems possess an enormous amount of work energy due to their inconceivably high information content. Natural ecosystems are sustainable on a long-term basis without our interference, and even able to tolerate certain levels of stress imposed by our activities. All activities require work energy. It is therefore crucial for the sustainability that we maintain the same amount of available work energy on Earth for the future generations. A sustainability analysis taking into considerations all facets of the concept should most probably include that we maintain almost the same cycling of the most important elements: carbon, nitrogen, phosphorus, and so on, and also that we maintain the biodiversity (which is an enormous capital of information) and the ecosystem services; but the two last concepts are partially covered by work energy [5].

We distinguish between different types of energy. The work energy of each type can be found as the product of a difference in potential and quantity. For instance, electrical work energy is the product of the difference in voltage times the charge, while potential energy is the difference in altitude (e.g. a waterfall) times the mass of water. The electrical energy of electricity and the chemical energy of fossil fuel possess practically $100 \%$ work energy, which we utilize in many ways in everyday life. Therefore, $1 \mathrm{kWh}$ of electricity has according to the unit conversion $3.6 \mathrm{MJ}$, and $1 \mathrm{~g}$ of petroleum contains about $42 \mathrm{~kJ}$ of work energy. The efficiency of the specific activities varies greatly depending on the technologies employed whereby less or more work energy is lost.

Fortunately, every day, we receive work energy from the sun in the form of solar radiation, which supports all ecological activities on the Earth. Both energy and material flows can be expressed as 
renewable or non-renewable work energy and are based on energy units. In this article, we aimed at assessing whether the development in a given area is sustainable or not by accounting the inputs and outputs of work energy. It is obviously important that we obtain as much work energy as possible out of the energies we use and that as little as possible is lost as waste heat to the surroundings. By accounting for the flows of energy and matter in terms of work energy, we obtain the advantage of sharing the same energy units, e.g. kJ or kWh. Thereby, we determine how much work energy of a system (the considered area or the entire globe) has changed per unit of time, which is much easier to determine than the absolute work energy of the entire system. Having accounted for energy and matter flows in this manner, we are able to identify areas of activities where large amounts of work energy are consumed and where work energies are applied with very low efficiencies. In such areas, it would be logical to take measures with the purpose to improve the work energy exploitation. This is yet another reason why work energy accounting is important.

Further details about the assessment of sustainability by the use of work energy can be found in [5], but in this article the next section details the results of the sustainability assessment of the Danish renewable energy Island Sams $\varnothing$, as it gives an illustrative example of the applicability of the methodology. For details about this case study, see $[4,6]$.

\section{THE RESULTS OF A SUSTAINABILITY ANALYSIS FOR THE DANISH ISLAND,} SAMS $\varnothing$

The analysis results for the Danish Island Sams $\varnothing$ are summarized in this section with a particular emphasis on the sustainability indicators discussed above. The case study will illustrate the use of work energy and one important element cycle, the carbon cycle, which will reveal the emission of the important green house gas carbon dioxide, and an analysis of the cycle will indicate where in the cycle it will be possible to introduce changes that could reduce the carbon dioxide emission. The method has been developed taking as a starting point the situation on the Danish Island of Sams $\varnothing$ because it is widely known for its efforts in connection to a project named 'Sustainable Energy Island', which started in 1997. The island has an area of $114 \mathrm{~km}^{2}$ and about 4,000 inhabitants plus tourism corresponding to about 1,000 additional inhabitants on an annual basis. The inhabitants have succeeded in making the island self-supporting regarding electrical work energy, which is mainly produced by 21 windmills on- and off-shore from the island. At the same time, part of the heating needed for buildings, which previously stemmed from oil burners, has been replaced by district heating and plants based on biomass burning (mainly straw, photo-thermal energy and photo-electric energy). Meanwhile, the island still has an import of fossil fuels necessary to maintain transport by ferry services, transport of goods to and from the island, transport on the island and heating in areas without access to renewable energy supplies.

The consumption and production of various types of energy on Sams $\varnothing$ are shown in Table 1.

Table 1: Consumption and production of various energy types in TJ (year 2007).

\begin{tabular}{lcc}
\hline Energy type & Consumption & Production \\
\hline Electricity & 285.7 & 386.0 \\
Heat & 140.4 & 66.3 \\
Gasoline + diesel & 86.3 & \\
\hline Total & 512.4 & 452.3 \\
\hline
\end{tabular}


Figures 1 and 2 [4,6] show the work energy balance of the island for year 2011 and 2020. The figure distinguishes between renewable and non-renewable energy and material. This shows that the island lost 193 TJ of work energy in year 2011, which is mainly due to export of electricity and food.

Figure 2 presents the work energy in year 2020 according to the plans that

1. The cars, trucks and tractors on the islands use biodiesel or electricity.

2. One-third of the work energy used by the ferries will be covered by electricity or biodiesel.

3. Five percent more renewable energy is produced on the island, mainly by wind turbines.

4. The remaining houses using fossil fuel will convert to electricity for heating.

According to this scenario, which illustrates how the assessment of work energy can be used as the management tool, the work energy lost by the island will be reduced by 153 TJ from 1,434 to 1,281 . But again, this is mainly due to export of electricity and food. We assume that the work energy capacity has not changed from 2011 to 2020, but is still 15,560 TJ. However, this is an approximation because as it will be shown by the carbon balance that a small amount of carbon is annually stored on the island. If it is assumed that organic matter contains $50 \%$ carbon and that $1 \mathrm{~g}$ of organic matter has $18.7 \mathrm{~kJ}$, then the amount of work energy stored due to the storage of organic matter on the island will be $<2 \%$ both in 2011 and 2020 .

Jørgensen et al. [4] used three indicators to interpret the above results:

1. Structural indicator, SI, is the ratio of work energy used for maintenance to the work energy capital on the island.

2. Renewable work energy ratio, R-ratio, is the ratio of renewable work energy to the total work energy.

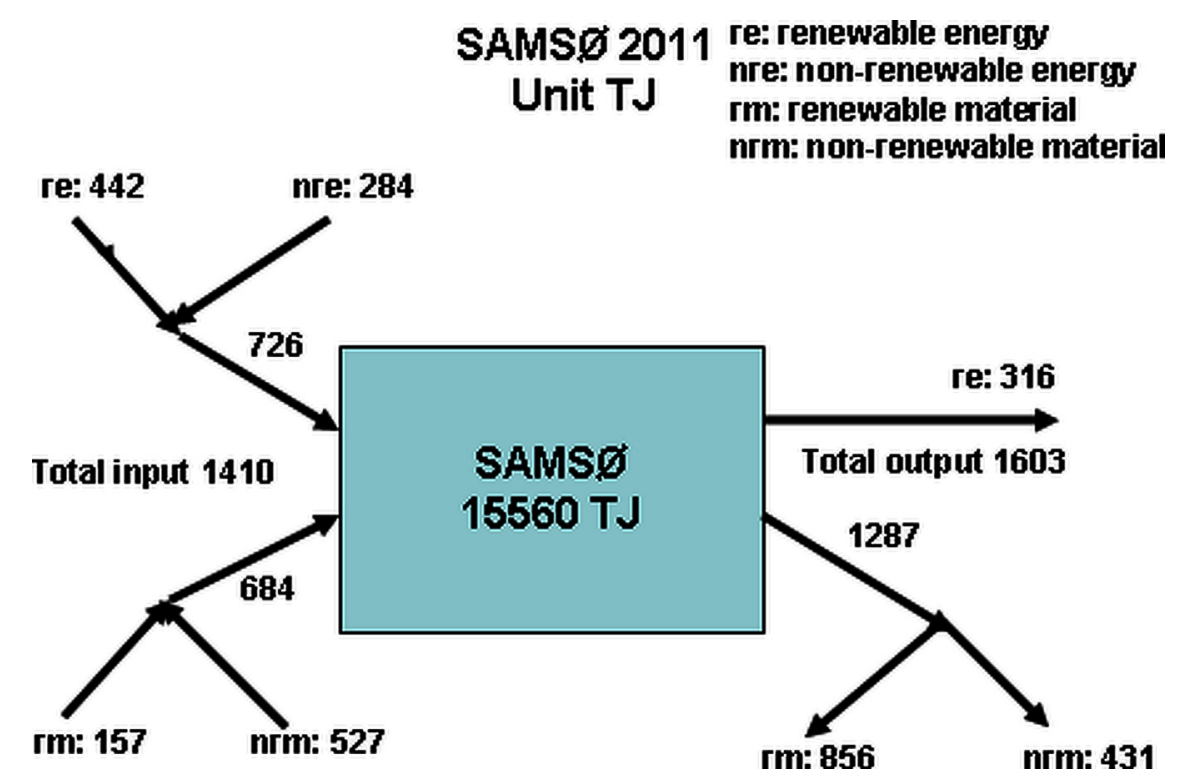

Figure 1: The input and output of renewable and non-renewable work energy both in the form of energy and materials. The island is losing 1,603-1,410 TJ of work energy per year or 193 TJ corresponding to about $1.2 \%$ of the work energy capital. 


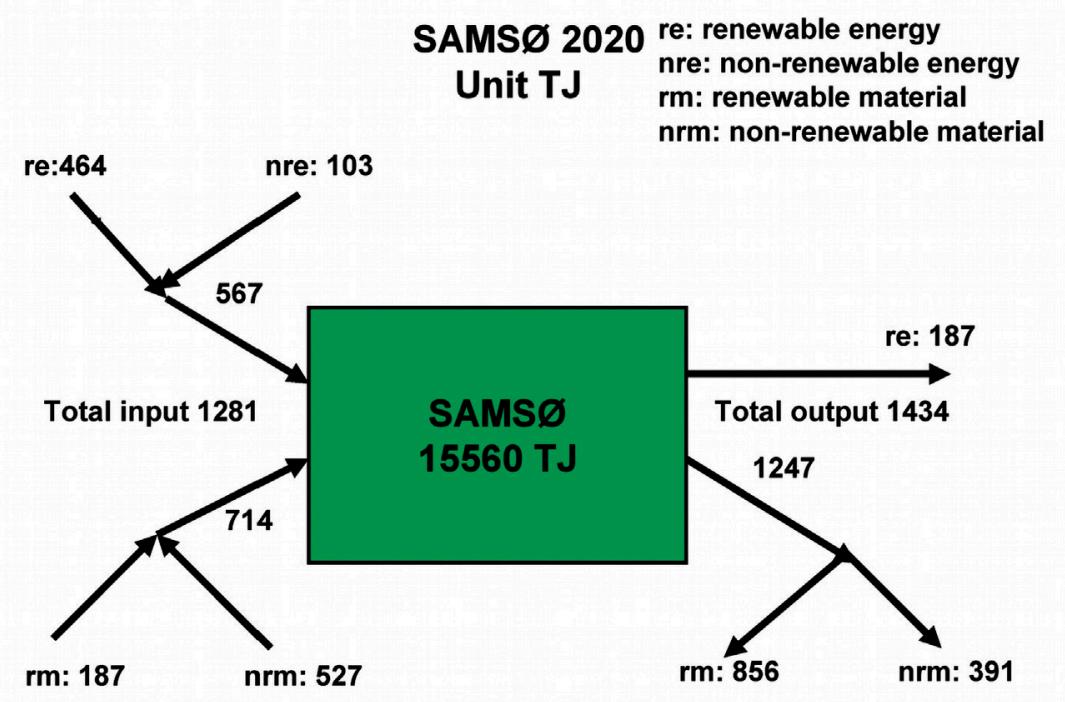

Figure 2: The work energy balance in year 2020, presuming that four projects are realized: all cars, trucks, and tractors use biodiesel or electricity, one-third of the work energy used by the ferries is covered by electricity or biodiesel, $5 \%$ more renewable energy is produced on the island and the last (few) houses using fossil fuel for heating will use electrical heating. Notice that the work energy exported from the island is reduced to $153 \mathrm{TJ}$ in year 2020 compared with 193 TJ in year 2011 as a consequence of increased internal use. The changes in the indicators SI, R-ratio, and E/I-ratio are shown in Table 2.

3. Export-import indicator, E/I ratio is the ratio of exported work energy to imported work energy (the work energy capacity (capital) was presumed unchanged). Those indicators for the island in years 2011 and 2020 are listed in Table 2

Table 2 shows the changes of the three indicators if the projects leading to an (almost) fossil-free island in year 2020 are realized. The E/I ratio could be 1.00 in year 2020, which would require that supplementary crops are produced. This would correspond to an accumulation of organic matter containing work energy on the island. The most ideal situation would be to have a high export of work energy, E/I, that can be utilized elsewhere but also a high accumulation of work energy on the island. The loss of work energy for maintenance is a question about the SI indicator. The long-term goal would be to obtain an R-ratio equal to 1.00. It will, however, be difficult to have all the work energy associated with materials becoming renewable before the entire global society is shifted to more than $90 \%$ recycling. The improvement of the SI is important because this means that while it costs $9 \%$ of the work energy capacity on the island in year 2011 to 'drive' the island, it costs only $8.2 \%$ to maintain the work energy capacity in year 2020 . The $0.8 \%$ work energy that is saved can either be used to increase the accumulation of work energy on the island or exported. In both cases, the work energy is not lost.

Replacing fossil fuel energy with renewable energy will provide a significant reduction in carbon dioxide emissions. This shift in energy policy is necessary, but not sufficient to ensure that the net 
Table 2: The sustainability indicator values in 2011 and 2020.

\begin{tabular}{lccc}
\hline Indicator & 2011 & 2020 & Ideal \\
\hline SI & 0.090 & 0.082 & Low \\
R ratio & 0.43 & 0.51 & $\geq 1.00$ \\
E/I ratio & 1.14 & $1.12^{\mathrm{a}}$ & $\mathrm{b}$ \\
\hline
\end{tabular}

at can be reduced to 1.00 by supplementary crops, corresponding to work energy accumulated on the island.

${ }^{b}$ High export of work energy and high accumulation of work energy on the island is most ideal.

carbon dioxide emission is zero for a considered area or region. It is necessary to obtain knowledge about all the processes involving carbon because significant carbon dioxide emissions result from a number of natural processes, for instance, decomposition of organic matter in nature, agriculture, and forestry. Fortunately, natural carbon emissions are balanced by carbon uptake through photosynthesis on an annual or decadal timescale. Therefore, a complete carbon balance for the area or region is needed to find the resulting net emission of carbon dioxide. A carbon model for the area or region is the best method to keep track of all the processes and transformations that finally lead to the emission of carbon dioxide or other greenhouse gases. The model should consider all the essential carbon pools and processes that transfer carbon from one pool to another.

A complementary study to the sustainability analysis on Samsø has developed a carbon cycling model for the island.

1. To demonstrate how a carbon cycle model (abbreviated as CCM) can be developed for a welldefined area.

2. To show how the CCM can be applied to find the net carbon dioxide emission.

3. To illustrate how the CCM can be applied as a powerful environmental management tool to answer such questions as: if a given planned or proposed project is implemented - in this case on Sams $\varnothing$ - what would be the consequences for the carbon dioxide emission and the emission of other greenhouse gases?

A CCM of the Siena district in Italy has previously been developed [7]. The experience gained developing this model has been applied in the Sams $\varnothing$ model. Generally, it can be concluded from the carbon model projects of Siena and Sams $\varnothing$ that a CCM as a supplement to a sustainability analysis is a useful tool in our effort to control the global climate changes that are resulting from our unrestrained growth policy. The CCM must keep track of the most important carbon sources, sinks, and pools, as well as consider all important processes that transfer from one pool to another. Figure 3 gives an image of the carbon pools and the processes that we would include in the Samsø CCM after the first considerations of what we should cover in the model. The figure represents what is denoted a conceptual diagram of the CCM. The boxes represent carbon pools and the arrows represent processes of carbon transfer. The applied model has 11 more state variables because the agro-production is divided into different products (corn, barley, potatoes, and so on), and nature is divided into wetlands, forest, and other natural areas. The pools include furthermore three fractions of carbon in soil based on decomposition rates: organic matter, fast decomposable organic matter, and soil carbon. More details about the model can be seen in Refs $[5,6,8]$. 


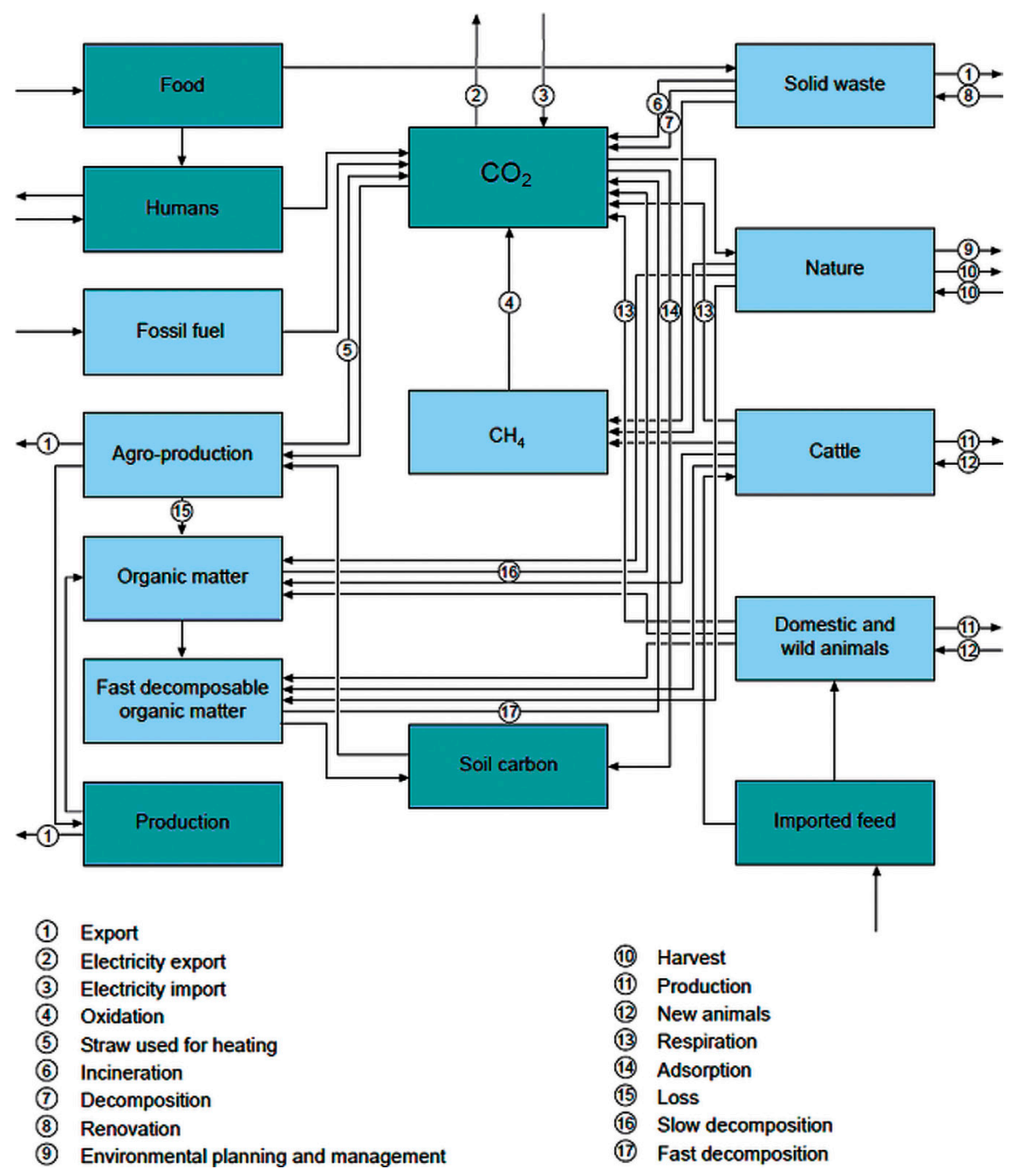

Figure 3: The conceptual diagram of the model as presented in the project proposal. The boxes represent carbon pools and the arrows represent processes of carbon transfer. The model used has 11 more state variables because the agro-production is divided into the different products (corn, barley, potatoes, and so on) and nature is divided into wetlands, forest, and other natural areas.

A model should always be developed on the basis of the available knowledge about the system in this case, the carbon pools on the island. From the Sams $\varnothing$ case, it is clear that knowledge about the external variables and the initial values of the state variables are needed before the model can be applied. Knowledge about the seasonal changes, the harvest time, and the production of various natural areas should be obtained as much as possible, as all knowledge can be used in the calibration phase of the model development. The climatic factors, temperature, solar radiation, and precipitation are also considered as external variables or forcing functions and should of course be known as functions of time or at least as seasonal variations from spring to summer to autumn to winter. 
The CCM is able to give two results that are essential for environmental management:

1. What is the net carbon dioxide emission (or uptake) on Samsø Island resulting from the many interacting processes?

2. Is Samsø losing or gaining carbon per year?

Figure 4 illustrates the answer to question A. The figure summarizes the carbon dioxide uptake by the photosynthesis of agricultural land and of nature. The release of carbon dioxide from fossil fuel use and respiration of humans and domestic animals is also shown. The use of straw and wood energy crops for heating will inevitably release carbon dioxide, although they are almost carbon neutral in the sense that an equal amount of carbon dioxide has been taken up during photosynthesis, but a minor amount of diesel oil is used for transportation. The amount taken up by the photosynthesis is, however, already included in the two sums of photosynthesis of agricultural production and the production of natural areas including bogs and forest. The methane produced by cattle and the wetlands is included in the model equations.

The numbers in Fig. 4 show that photosynthesis on Sams $\varnothing$ removes carbon dioxide from the atmosphere at an amount of 26,460 tC per year. This is able to compensate more for the soil respira-

\section{Annual Exchange of Carbon Dioxide with the Atmosphere}

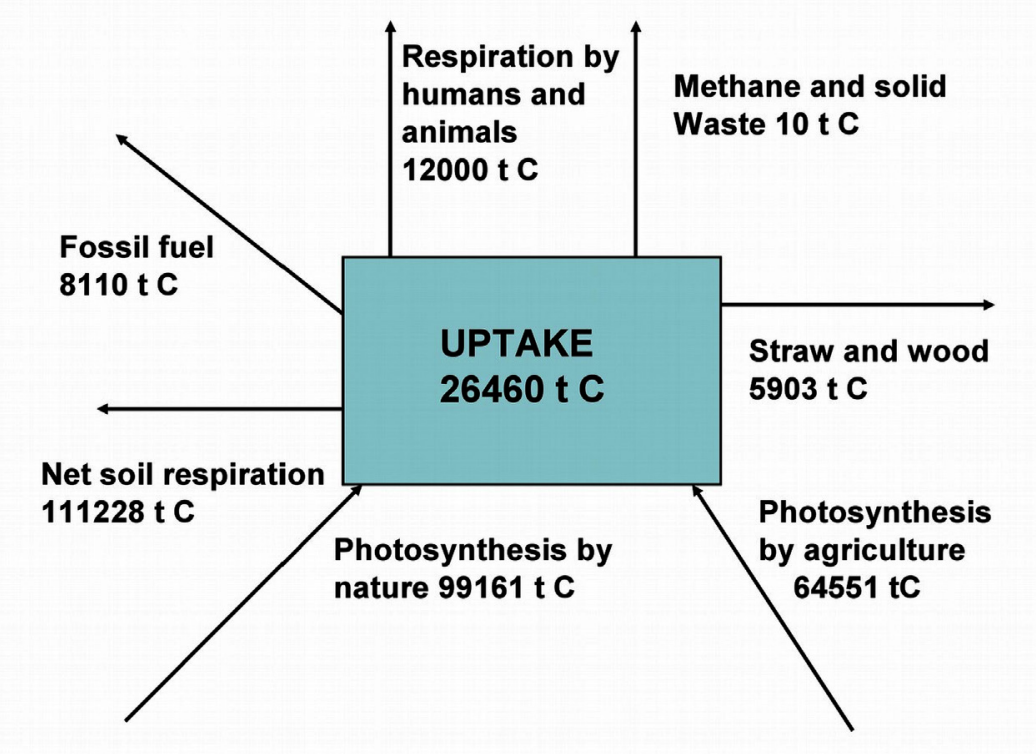

Figure 4: Results of the CCM show that Samsø sequesters 26,400 tC/year from the atmosphere: The processes leading to this result are summarized in the figure. The processes producing carbon dioxide are: combustion of fossil fuel, combustion of straw and wood, respiration of humans and animals, methane, decomposition of solid waste, and respiration of organic matter in soil, mainly by microorganisms. The processes that take carbon dioxide from the atmosphere are: photosynthesis of agricultural land and of the nature on Sams $\varnothing$. 
tion, the use of fossil fuels, the use of biomass fuels, and the respiration of humans and domestic animals. From this, it can be concluded that the Island Samsø is a net sink for carbon, capturing already today around 26,500 tC/y. Notice that the results are based on bogs and forests occupying the same area year after year, and that they inevitably will increase the carbon pool slightly due to growth. The amount is known from wetland and forest ecology and is in this case estimated to be about totally $5,000 \mathrm{tC} /$ year.

Figure 5 shows the import-export balance of carbon for Samsø Island, answering question B. The island imports carbon from the atmosphere (the net result of Fig. 4), by using fossil fuels, in the food for humans and the feed for pigs, and it exports carbon through agricultural production and by solid waste exported to Jutland for incineration. Overall, the result of the import-export balance of carbon for the island is an increase of 1,764 tC per year (Fig. 5). This means, considering the standard deviation of the numbers applied in the model, that the carbon amount on the island is almost constant and the carbon transfer processes are in balance.

The CCM can be applied to answer relevant environmental management questions about the influence on the carbon balance of possible changes. One relevant question about possible changes can be used as illustrations.

The question: How will the carbon dioxide uptake, the CCM results, and the total carbon balance of the island be changed if a fossil fuel free island is introduced and the supplementary crops are increased by 5,000 tC/y? The answers are shown in Fgs 6 and 7. The total carbon dioxide uptake is about 50\% higher than in the present situation (see Fig. 4 and compare with Fig. 6). The carbon balance of the island (Fig. 7) is increased almost by 5,000 tC/y due to supplementary crops use, and the uptake of carbon is also increased by almost 5,000 tC/y. A small amount of the 5,000 $\mathrm{t}$ carbon stored in the soil will decompose. The results show that introducing fossil fuel free measures on the island influences only the carbon dioxide uptake and not the C-balance of the island, while the increase of supplementary crops has influence on both the carbon dioxide uptake and on the C-balance of the island.

The effects of the two examined changes can be seen as positive under all circumstances. Sams $\varnothing$ was in year 2011 more than carbon dioxide neutral due to the introduction of renewable energy

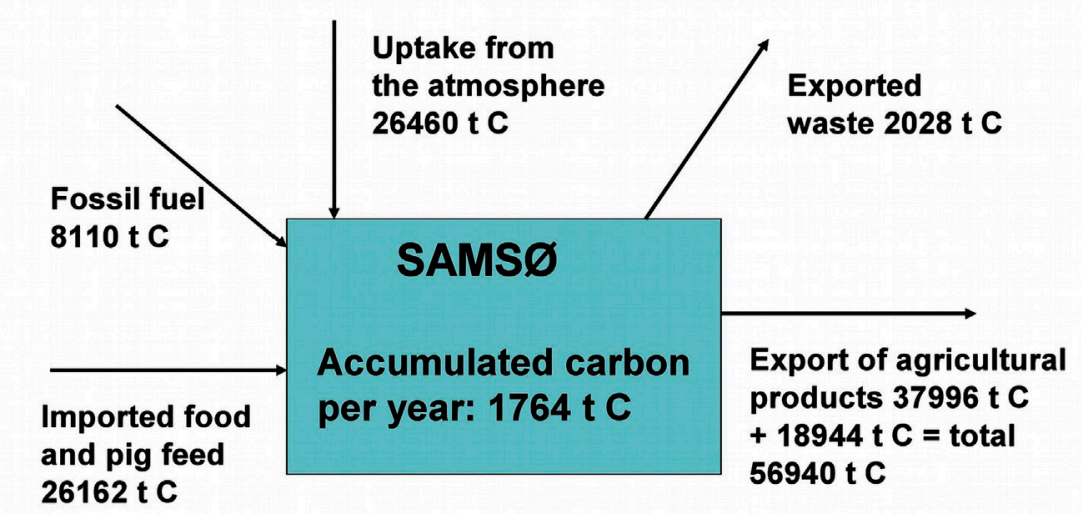

Figure 5: The export and import of carbon to the island of Sams $\varnothing$ are shown. The $\mathrm{C}$ on the island is almost in balance, as the difference between import and export is only about $3 \%$. There is an accumulation of carbon on Sams $\varnothing$ according to the figure (1,764 tC/year). 


\section{Annual Exchange of Carbon Dioxide with the Atmosphere}

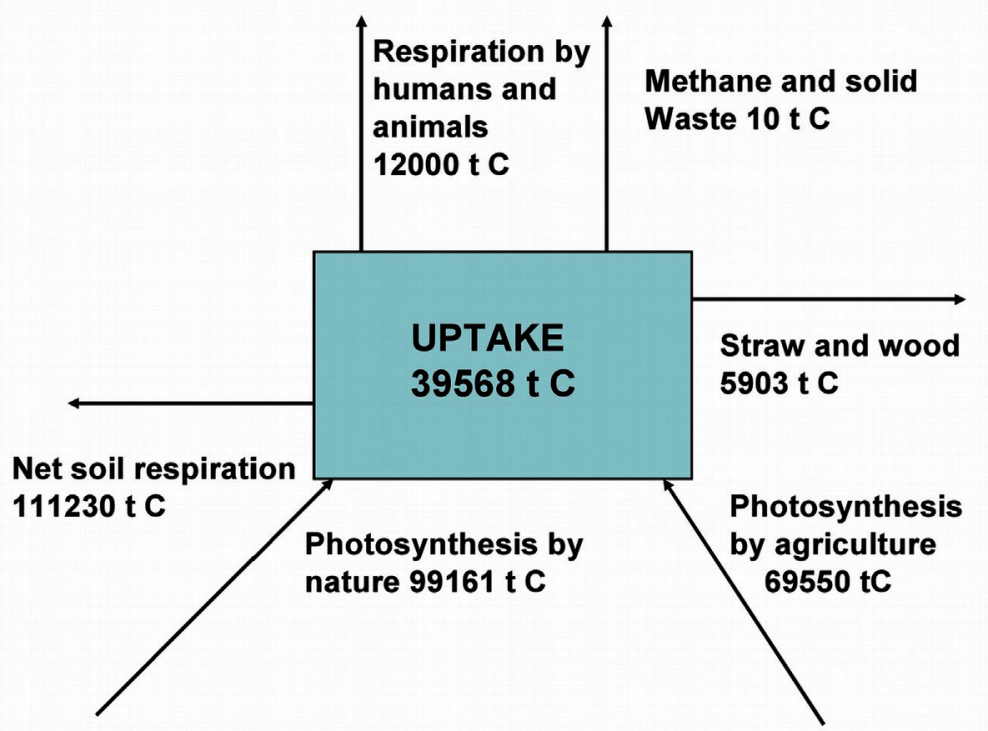

Figure 6: Results of the CCM by increasing supplementary crops by 5,000 tC/ and eliminating fossil fuels from the island. The uptake is now almost 40,000 tC/y, which is about 13,000 tC greater than the results shown in Fig. 4 .

\section{Annual C-balance Samsø}

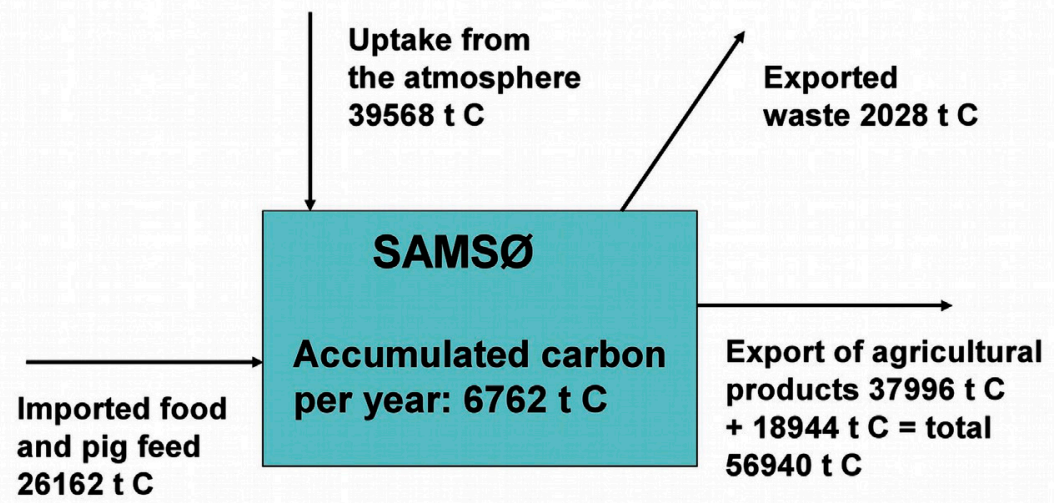

Figure 7: The carbon balance of the island Sams $\varnothing$ when the supplementary crops are increased by $5,000 \mathrm{f} / \mathrm{y}$ and a fossil fuel free island is introduced. Notice that more than $39,500 \mathrm{tC} / \mathrm{y}$ is taken up and that the carbon pool on the island is increased by more than $6,700 \mathrm{tC} / \mathrm{y}$. 
because about 26,000 tC is taken up by the island as carbon dioxide per year. By introducing supplementary crops $(5,000 \mathrm{tC}$ per year) and by making the island fossil fuel free, it becomes possible that Sams $\varnothing$ takes up more than 39,000 tC per year. This entails that the island removes about 6,000 tC per year as carbon dioxide more than the island releases even with inclusion of the carbon dioxide released elsewhere but originating from the island's food products.

\section{GLOBAL SUSTAINABILITY ANALYSES}

The introduction of renewable energy is urgently needed as soon as possible if we want to limit global warming to $2^{\circ} \mathrm{C}$. As the changes of climate means radically different conditions for humans and all life on the Earth, a sustainability analysis should include a CCM to allow us to focus on the processes that are causing the greatest emissions of greenhouse gases, mainly carbon dioxide and methane. A CCM will, furthermore, be able to identify processes other than fossil fuel combustion that contribute emissions and even suggest how control of these processes could be used to obtain additional reduction of greenhouse gas emissions.

A global sustainability analysis using work energy has been carried out in [5]. The analysis was not very accurate as it is hardly possible to get the data needed for a more accurate assessment. The well-known book The Limits to Growth [9] gives another global sustainability analysis, which shows that if we do not accept the physical laws about mass and energy conservations, it means that we do respect the limits to growth, the development will inevitably be very far from sustainable. Jørgensen et al. [4] have analyzed the possibilities to make the development sustainable by an action plan that considers the limits to growth. A model similar to the model applied in The Limits to Growth was applied for this analysis; see Fig. 8. The global model has eight state variables describing global development under different conditions. We started the model simulation in year 2000, so the initial conditions for the state variables at that time (when $\mathrm{t}=0$ ) are taken from the Club of Rome's growth model runs up until that point.

The predictions made by the Club of Rome from 1972 in the beginning of this century are largely accurate. A similar model was also applied in [10]. It was used in 1993 to perform the first test of scenarios based on additional support to the developing countries, particularly for birth control and appropriate pollution control. A model's complexity can always be discussed, and there are a few Club of Rome models that have slightly more state variables. A more complex model requires, however, more knowledge or more information and as the global models used here and by the Club of Rome inevitably have a high statistical uncertainty and only should be used to compare different scenarios, it seems important to select a model of a balanced or at least not a too high complexity. The eight state variables of the model are:

1. The production capacity of the industrialized countries is denoted by CAPI. Meadows et al. [9] applies a reference industrial potential in year 1962 of 100 with $75 \%$ in the industrialized countries and 25\% in the developing countries. Under this scenario, the increase that has taken place since 1962 is the initial value for year 2000, such that CAPI $=340$.

2. The production capacity of the developing countries, CAPD, has an initial value in year $2000=$ 110 according to the reference in 1962 as indicated above.

3. The pollution level, POLL, has an initial value for year 2000 of 100 . This is a relative value that increases with the production level and decreases with pollution abatement.

4. The available resources, RESS, has an initial value of 20,000, which corresponds to about 200 years of consumption with the present initial rate of using resources and about 100 years with the 


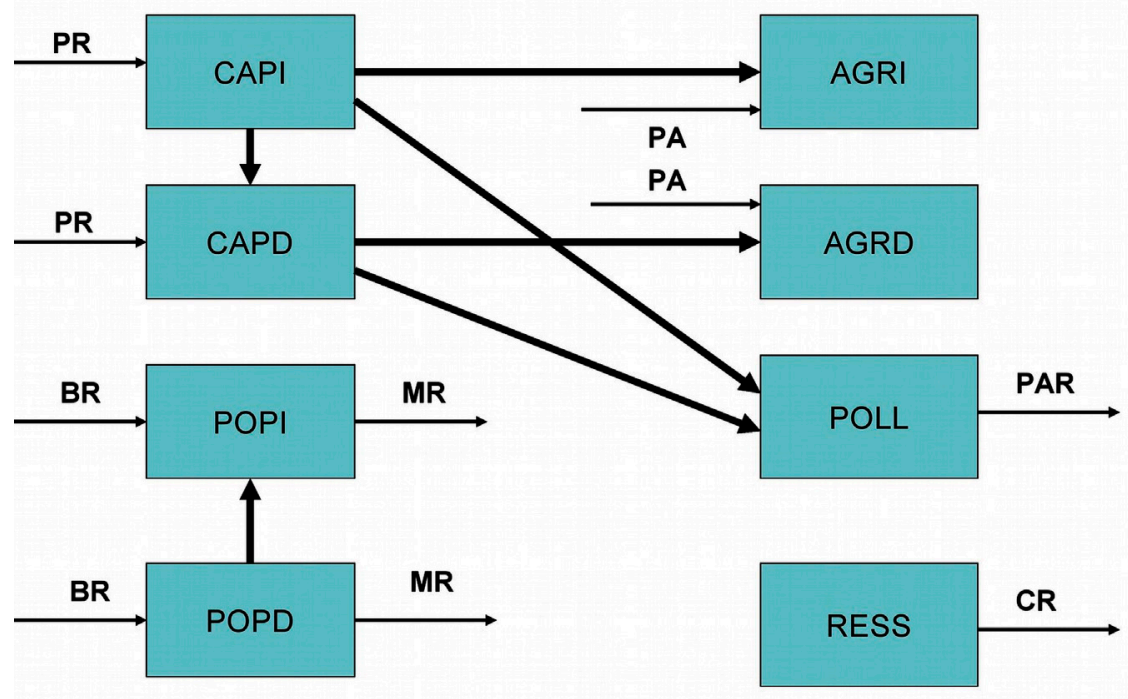

Figure 8: A simplified conceptual diagram of the global model applied is shown. Only the eight state variables, the direct inputs and outputs, and the transfers are shown, but not the controls. In addition, all the state variables have several important controls of rates by the other state variables. The annual increase in the production capacities, also denoted the interest rate, are indicated as PR. BR and MR are birth rate and mortality rate regulating the population size. PA indicates the increase in the annual agricultural production of the industrialized and the developing countries. The pollution level increases proportional to the production (PR) and decreases due to pollution abatement (PAR); CR is the annual reduction in the resources.

expected average value of using the resources during the 21th century, based on business as usual - it means an increasing rate year by year. An annual increase of resource use of about $1.5 \%$ is presumed, when the resources will be depleted in about 100 years.

5. The annual agricultural production capacity in the developing countries, AGRD, is set to 100 by year 2000. This initial production is of the order of $20-25 \%$ lower than needed to give the entire present population in the developing countries a sufficient diet both quantitatively and qualitatively.

6. The annual agricultural production capacity in the industrialized countries, AGRI, is also a relative value 100 in year 2000.

7. The population in the developing countries, POPD, is 5,000 million in the year 2000, of which 300 are included in the population of the industrialized countries, because the United Nations statistics indicate approximately 300 million for year 2000, particularly in the BRIC countries they have a standard of living, birth rate, mortality rate, and consumption on the same level as the industrialized countries. Therefore, POPD in year 2000 is equal to 4,700 million.

8. The population in the industrialized countries, POPI, in the year 2000 is 1,000 million (North America, Europe, Japan, Australia, and New Zealand) plus 300 million to account for the middle-class population in the BRIC countries. It means a total of 1,300 million people. 
The eight chosen state variables are consistent with the Meadows et al. (1992) model and the model used in Jørgensen [10]. The dynamic simulation software STELLA was used to implement the model and to generate the results. The equations are accounting for the following observations and knowledge about the global development:

- Pollution affects agricultural production, industrial production, and population mortality both in the industrialized and developing countries.

- Production in the industrialized countries is decreasing slightly every year accounting for a materialistic saturation, for a shifting from quantitative to qualitative production and for the difficulties to continue an increase in the production when it already has reached a high level.

- Production in the developing countries is increasing slightly every year to express that it is easier to increase production on a low level than on a high level.

- The production capacities, CAPI and CAPD, are presumed to give an interest rate of $7.5 \%$. This rate is the same as applied in Limits to Growth. This means that the production capacity is increasing in both the industrialized and developing countries by $7.5 \%$, provided that we do not consider other factors influencing the production capacity. The rate is, however, increased by investment in education and decreased with pollution-level increase and resource reduction. The increase in the annual agricultural production is considered financed by the interest rate..

- Similarly, consumption decreases over time slightly in the industrialized countries because they are closer to the saturation and increases over time slightly for the developing countries as they have a significant need for a higher consumption. 0.65 times this interest rate is used in both the industrialized and developing countries for consumption (food, cloths, cars, housing, heating, electricity, other goods, and so on).

- The interest rate is furthermore used to determine the pollution abatement and the investment in education, innovation, and research.

The actions that are presumed to be taken and are introduced in the global model to see their effects, are as follows:

1. All industrialized countries with a GNP/capita of more than 20,000 dollars per year pay $0.8 \%$ of GNP increase by $0.04 \%$ per year to the developing countries. It is strongly recommended by UN.

2. Ten percent of this support is applied for family planning.

3. Forty percent of the support is used to improve education in the developing countries.

4. $2.5 \%$ of the production value is allocated to pollution control.

5. The pigovian tax (also called green tax $=$ tax on resources or on waste discharge) is increased to $8 \%$ in average. The idea is of course to promote the three r's: recycling, reuse, and reduction and thereby obtain a much slower depletion of the resources.

6. A massive investment, at least $10 \%$ of GNP, is made in education, innovation, and research in the industrialized countries. It has been shown by UNESCO that investment in education, innovation, and research is the most profitable investment for a country.

The results of these actions are based upon global known statistic relationships, which are published in [4].

The results of the global model applied for the business as usual scenario - it means that the present low support to the developing countries, no support for family planning and for education, $1 \%$ only used for pollution abatement, a pigovian tax of $5 \%$ and support for education, innovation and 
Table 3: Results of the global model applied on two scenarios: business as usual and the six-point action plan mentioned in the text (summary from [4]).

\begin{tabular}{lcccc}
\hline State variables & \multicolumn{2}{c}{ Business as usual } & \multicolumn{2}{c}{ 6-point action plan } \\
\hline & 2050 & 2100 & 2050 & 2100 \\
\hline POLL & $42 \%$ & $+80 \%$ & $+80 \%$ & $+4 \%$ \\
RESS & $-10 \%$ & $-16 \%$ & $-3 \%$ & $-6 \%$ \\
POPI $\left(10^{\wedge} 6\right)$ & 1,500 & 1,800 & 1,590 & 1,900 \\
POPD $\left(10^{\wedge} 6\right)$ & 9,000 & 14,800 & 6,800 & 3,800 \\
GNP/cap dev C & 550 & 2,180 & 3,200 & 19,500 \\
\hline
\end{tabular}

research of 5\% are applied - and for the scenario based on the above-mentioned action plan are found. A comparison of these results is summarized in Table 3. The development of the pollution level, the resources, and the populations (four state variables) and the GNP/capita in industrialized and developing countries are shown. The changes in $\%$ for the pollution level and the resources and the absolute number for the populations and the GNP/capita are shown for year 2050 and year 2100 . As mentioned above, the number of inhabitants in developing countries and industrialized countries is 5,000 and 1,300 million, respectively, in year 2000. The GNP/capita is about 25,000 $\$ / y$ in the industrialized countries in year 2000 and about $\$ 2,800 /$ year in the developing countries.

Overall, it is possible to conclude that the six changes introduced are able to provide acceptable results for the global population, both in the industrialized and developing countries. The obvious question is: Are the model results at least approximately reliable? The sensitivity of the effects of each of the six changes is examined and can be used to estimate the uncertainty of the model results. Based upon the examination of the sensitivity, it can be concluded that the results should only be considered approximate on the one side but that they on the other side show a very clear tendency to change the development by introduction of the six-point action plan.

While all the equations applied are reasonable, have causality, and are based on the statistical information that is available, they still have an uncertainty that may affect the results of the model scenarios because the statistical data are unfortunately limited. In this context, it is important to underline that the presented results are only scenarios - not predictions. The scenarios require that all the six changes are realized and in a dynamic world other unexpected changes may take place. Therefore, the results of the scenarios tell us the approximately relative effect of the implemented changes compared with the business as usual scenario. Of course, the model cannot account for the unexpected natural or human-controlled changes that we do not have the slightest idea about today, but on the other hand, new experience will be gained and can be applied to adjust the model currently and thereby increase the reliability of the model results.

\section{CONCLUSIONS}

It has been shown that it is possible to perform a sustainability analysis by the use of work energy as an indicator. Work energy is important for sustainability analyses because all activities require work energy. It means that work energy is necessary to include in a sustainability analysis, although it may not be sufficient. It is necessary to supplement the use of work energy with the development of the most important element cycles, to ensure that there is no unbalance for the most important elements. The use of work energy for the assessment of the sustainability has been developed for a Danish 
island, Sams $\varnothing$, that is using renewable energy, and it has been supplemented by the use of a carbon cycling model that is important because it can calculate the carbon dioxide emission and indicate the sources to this emission. In other cases, it may be important to include also other element cycles and it cannot be excluded that the maintenance of the biodiversity and the services of the most important ecosystems in the focal area are important to consider in a more complete sustainability analysis.

The use of work energy as indicator for a global sustainability analysis has carried through (Jørgensen, 2006), although the accuracy of the estimation was relatively low due to lack of information. The Club of Rome's publication The Limits to Growth from 1972 can be considered another attempt to perform global sustainability analysis. This article has been able to show by the use of a global model similar to the one used by the Club of Rome, so that a better global sustainability can be achieved by (1) more support from the industrialized countries to the developing countries and a massive use of this support for family planning and education, (2) more investment in pollution abatement, (3) higher pigovian tax to enhance recirculation and reuse of the resources, and (4) generally more investment in education, innovation, and research in all countries.

Generally, it can be concluded that modeling is an indispensable tool for the development of sustainability analysis and that the models as demonstrated in the article can be used as a powerful management tool.

\section{REFERENCES}

[1] Farley, H.M. \& Smith, Z.A., Sustainability - It Is Everything, Is It Nothing? Routledge: London and New York, pp. 176, 2014.

[2] United Nations World Commission Environment and Development, Our common future. Brundtland Commission Report on Environment and Development, pp. 360, 1987.

[3] Neumayer, E., Weak Versus Strong Sustainability, 2nd edn., Edward Elgar: Cheltenham, UK, pp. 272, 2003.

[4] Jørgensen, S.E., Fath, B., Nielsen, S.N., Pulselli, F., Fiscus, D. \& Bastiononi, S., Flourishing Within the Limits to Growth, Earthscan: London, pp. 290, 2015.

[5] Jørgensen, S.E., Eco-exergy as Sustainability, WIT Press: Southampton, UK, pp. 208, 2006.

[6] Nielsen, S.N. \& Jørgensen, S.E., Evaluation of local sustainability. The case study of Sams $\varnothing$ (DK) 2011. Scientific and Technical Report, 2013, pp. 322. Summary of this report and the development of a carbon model are available, see, for instance, the webpage of Energy Academy Sams $\varnothing$ or the webpage wrlsej.dk.

[7] Marchi, M., Jørgensen, S.E., Bacares, E., Corsi, I., Marchettini, N. \& Bastiononi, S., Modelling the carbon cycle of Siena Province (Tuscany, central Italy). Ecological Modelling, 225, pp. 40-60, 2012. http://dx.doi.org/10.1016/j.ecolmodel.2011.11.007

[8] Jørgensen, S.E. \& Nielsen, S.N., A carbon cycling model developed for the renewable Energy Danish Island, Samsø. Ecological Modelling, 306, pp. 106-120, 2015 http://dx.doi.org/10.1016/j.ecolmodel.2014.06.004

[9] Meadows, D.H., Meadows, D.L., Randers, J. \& Behrens, III W.W., The Limits to Growth, Earth Island Limited, London, pp. 205, 1972.

[10] Jørgensen, S.E., The application of global models for comparison of different strategies on sustainable living, Ecological Economics, 11(1), pp. 1-8, 1994.

http://dx.doi.org/10.1016/0921-8009(94)90044-2 